\title{
The phosphodiesterase 5 inhibitor sildenafil decreases the proinflammatory chemokine IL-8 in diabetic cardiomyopathy: in vivo and in vitro evidence
}

\author{
S. Giannattasio ${ }^{1} \cdot$ C. Corinaldesi ${ }^{1,2} \cdot$ M. Colletti $^{1} \cdot$ L. Di Luigi ${ }^{1} \cdot$ C. Antinozzi ${ }^{1} \cdot$ T. Filardi $^{3} \cdot$ S. Scolletta ${ }^{4} \cdot$ S. Basili ${ }^{5}$. \\ A. Lenzi ${ }^{3} \cdot$ S. Morano ${ }^{3} \cdot$ C. Crescioli ${ }^{1}$
}

Received: 29 July 2018 / Accepted: 1 November 2018 / Published online: 10 November 2018

(c) The Author(s) 2018

\begin{abstract}
Purpose Interleukin (IL)-8 is a proinflammatory C-X-C chemokine involved in inflammation underling cardiac diseases, primary or in comorbid condition, such diabetic cardiomyopathy (DCM). The phosphodiesterase type 5 inhibitor sildenafil can ameliorate cardiac conditions by counteracting inflammation. The study aim is to evaluate the effect of sildenafil on serum IL-8 in DCM subjects vs. placebo, and on IL-8 release in human endothelial cells (Hfaec) and peripheral blood mononuclear cells (PBMC) under inflammatory stimuli.

Methods IL-8 was quantified: in sera of (30) DCM subjects before (baseline) and after sildenafil (100 mg/day, 3-months) vs. (16) placebo and (15) healthy subjects, by multiplatform array; in supernatants from inflammation-challenged cells after sildenafil $(1 \mu \mathrm{M})$, by ELISA.

Results Baseline IL-8 was higher in DCM vs. healthy subjects ( $149.14 \pm 46.89$ vs. $16.17 \pm 5.38 \mathrm{pg} / \mathrm{ml}, p<0.01)$. Sildenafil, not placebo, significantly reduced serum IL-8 $(23.7 \pm 5.9 \mathrm{pg} / \mathrm{ml}, p<0.05$ vs. baseline). Receiver operating characteristic (ROC) curve for IL-8 was 0.945 (95\% confidence interval of 0.772 to $1.0, p<0.01$ ), showing good capacity of discriminating the response in terms of drug-induced IL- 8 decrease (sensitivity of 0.93 , specificity of 0.90 ). Sildenafil significantly decreased IL-8 protein release by inflammation-induced Hfaec and PBMC and downregulated IL-8 mRNA in PBMC, without affecting cell number or PDE5 expression.

Conclusion Sildenafil might be suggested as potential novel pharmacological tool to control DCM progression through IL-8 targeting at systemic and cellular level.
\end{abstract}

Keywords IL-8 · Sildenafil · Diabetes · Cardiomyopathy · Inflammation

\section{Introduction}

Low-grade inflammation is a critical component of chronic metabolic disorders such as type 2 diabetes (T2D) and is tightly associated with diabetes-induced vascular and cardiac complications [1]. This general inflammatory status,

S. Giannattasio, C. Corinaldesi and M. Colletti equally contributed. recently referred to as 'metaflammation', is common to several

\section{Crescioli}

clara.crescioli@uniroma4.it

1 Department of Movement, Human and Health Sciences, Section of Health Sciences, Unit of Endocrinology, Università degli Studi di Roma "Foro Italico", 00135 Rome, Italy

2 Institute for Cancer Genetics, University of Columbia, New York, USA
3 Department of Experimental Medicine, Policlinico Umberto I, Sapienza University of Rome, Rome, Italy

4 Department of Medical Biotechnologies, University of Siena, Siena, Italy

5 Department of Internal Medicine and Medical Specialties, Policlinico Umberto I, Sapienza University of Rome, Rome, Italy 
comorbid conditions-cardiomyopathy, diabetes, atherosclerosis - and is usually characterized by T helper 1 (Th1) type immune dominance and related biomediators, such as cytokines and chemokines [2]. Several Th1 type biomolecules are engaged in inflammatory processes at systemic, cellular and biomolecular levels, i.e., interleukin (IL)-1, IL-6, IL-8, IL-10, IL-12, tumor necrosis factor (TNF) $\alpha$, and interferon (IFN) $\gamma$. In particular, IL-8 is present since early stages of inflammatory response and remains active for long time [3]; remarkably, this chemokine seems widely involved in cardiac disease, either primary or secondary to dysmetabolism [4]. Indeed, IL-8 serum level is connected with atherosclerosis processes linked to cardiovascular events, in association with baseline cardiovascular risk [5]. Furthermore, higher circulating IL-8 level found in T2D patients vs. non-diabetic subjects was associated with worse inflammatory and cardiometabolic profile [6].

Nowadays, the class of drugs inhibiting phosphodiesterase type 5 (PDE5i), including sildenafil, vardenafil, tadalafil and avanafil, commonly used to treat erectile dysfunction (ED), is documented to exert blunting effects onto Th1-driven processes and biomediators, likely through cGMP/cAMP stabilization $[7,8]$. In line with those observations, we have previously reported that sildenafil in diabetic cardiomyopathy (DCM) significantly decreased Th1 type chemokine CXCL10 level, in blood and in human cardiomyocytes [9]. PDE5i seem, indeed, to elicit protective effects in several heart dysfunctions (either primary or secondary to other diseases) such heart failure, ischemia/reperfusion injuries, infarct, ventricular arrhythmias, cardiopulmonary bypass [10-12].

In light of this evidence, it has been hypothesized that PDE5i-elicited cardioprotective effects may rely not only on their undeniable vasoactive action but also on their antiTh1 type inflammatory processes. Considering the pivotal role of IL-8 during inflammation-induced tissue/cell damage in cardiac diseases, herein we aim to investigate whether sildenafil can target IL-8 level in T2D subjects with DCM and in human endothelial and peripheral immune cells under maximal Th1 inflammatory challenge. To this purpose, we measured IL-8 in sera from T2D patients at the onset of cardiomyopathy secondary to diabetes, before and after chronic treatment with sildenafil (100 mg/day for 3 months) vs. placebo. Baseline chemokine levels were measured in sex- and age-matched healthy subjects. In addition, we investigated the effect of sildenafil onto IL-8 released by human endothelial and immune cells activated by IFN $\gamma+\mathrm{TNF} \alpha$ or phytohaemagglutinin (PHA), respectively.

\section{Materials and methods}

\section{Chemicals}

Plastic for cell cultures and disposable filtration units were purchase from Corning (Milan, Italy). Dulbecco-modified eagle medium (DMEM)/Ham's F-12 medium (ratio 1:1) with and without phenol red, RPMI-1640 Medium, phosphate-buffered saline $\mathrm{Ca}^{2+} / \mathrm{Mg}^{2+}$-free (PBS), bovine serum albumin (BSA) fraction $\mathrm{V}$, antibiotics, EDTA-trypsin solution, Bradford reagent were from Sigma-Aldrich Corp. (St. Louis, MO, USA). Fetal bovine serum (FBS) was from Hyclone (Logan, UT, USA). Recombinant human interferon (IFN- $\gamma$ ) and recombinant human Tumor Necrosis Factor alpha $(\mathrm{TNF} \alpha)$ were from Peprotech ${ }^{\circledR}$ (RockyHill, NJ, USA). For RNA extraction, TRIzol RNA isolation reagent was purchased by Ambion ${ }^{\mathrm{TM}}$; for reverse transcription $10 \mathrm{mM}$ dNTP mix, random primers, RNaseOUTTM Ribonuclease inhibitor and SuperScript ${ }^{\circledR}$ III Reverse were purchased from Invitrogen. SYBR ${ }^{\circledR}$ Green PCR Master Mix for qPCR was from Life Technologies ${ }^{\mathrm{TM}}$ (Applied Biosystems $^{\circledR}$ ). All reagents for SDS-PAGE were from Millipore (Billerica, MA, USA). L-Glutamine was from Gibco Laboratories (Grand Island, NY). Polyclonal rabbit antiPDE5 and monoclonal mouse anti- $\beta$-actin were from Santa Cruz (CA, USA).

\section{Subjects}

Frozen samples from 46 subjects with DCM were analyzed (Clinical Trial Registration-URL: http://www. clinicaltrials.gov. Unique identifier: NCT00692237) [13]. The protocol was approved by Hospital Ethics Committee Policlinico Umberto I-Sapienza University Hospital of Rome. This was a randomized controlled trial with patients allocated to receive $100 \mathrm{mg} /$ day sildenafil for 3 months (30 subjects) or placebo (16 subjects). Eligible men with T2D were recruited from the outpatient of Policlinico Umberto I-Sapienza University Hospital of Rome, the inclusion criteria were: T2D $>1$ year; normal blood pressure (BP) or treated hypertension with achievement of a target of $\leq 130 / 80 \mathrm{mmHg}$; glycated hemoglobin (HbAlc) $<10 \%$; body mass index $(\mathrm{BMI})<40$; Table 1 summarizes patient characteristics. The exclusion criteria were: prior or current use of PDE5i; use of exogenous insulin, thiazolidinediones, or spironolactone; substance abuse; history of cardiovascular disease, proliferative retinopathy, autonomic neuropathy; symptoms or signs of ischemic heart disease during cardiac evaluations at enrollment; contraindications to sildenafil use or cardiac magnetic resonance (CMR) imaging. Concomitant medications (anti-hypertensives, 
Table 1 Clinical characteristics of the study populations

\begin{tabular}{lll}
\hline Variable & $\begin{array}{l}\text { Diabetic cardio- } \\
\text { myopathy sildenafil } \\
\text { arm }\end{array}$ & $\begin{array}{l}\text { Diabetic cardio- } \\
\text { myopathy placebo } \\
\text { arm }\end{array}$ \\
\hline Numbers & 30 & 16 \\
Age (years) & $61.4 \pm 1.4$ & $60.7 \pm 1.3$ \\
BMI $\left(\mathrm{kg} / \mathrm{m}^{2}\right)$ & $28.4 \pm 0.9$ & $27.6 \pm 0.8$ \\
Glycemia $(\mathrm{mmol} / \mathrm{L})$ & $8.4 \pm 1.9$ & $8.2 \pm 1.6$ \\
HOMA-index & $6.3 \pm 0.8$ & $7.5 \pm 0.8$ \\
HbAlc $(\%)$ & $7.9 \pm 0.2$ & $7.3 \pm 0.3$ \\
Total cholesterol (mmol/L) & $4.8 \pm 1.0$ & $4.4 \pm 0.2$ \\
HDL cholesterol (mmol/L) & $1.05 \pm 0.2$ & $1.2 \pm 0.06$ \\
LDL cholesterol (mmol/L) & $3.01 \pm 0.98$ & $2.43 \pm 0.20$ \\
Triglycerides (mmol/L) & $1.4 \pm 0.7$ & $1.4 \pm 1.1$ \\
Mean systolic BP (mm Hg) & $136.1 \pm 2.2$ & $131.4 \pm 2.8$ \\
Mean diastolic BP (mm & $79.7 \pm 1.6$ & $78.9 \pm 1.4$ \\
Hg) & & \\
LVMi (g/m ${ }^{2}$ ) & $124.6 \pm 4.7$ & $114.1 \pm 5.9$ \\
EDVi (mL/m $\left.{ }^{2}\right)$ & $61.4 \pm 1.7$ & $60.76 \pm 2.3$ \\
Ejection Fraction $(\%)$ & $61.6 \pm 1.5$ & $59.1 \pm 1.90$ \\
BNP (pmol/L) & $2.6 \pm 0.3$ & $3.02 \pm 1.0$ \\
NT proBNP (pg/ml) & $70 \pm 11.9$ & $72.2 \pm 18.5$ \\
Serum IL-8 levels (pg/ml) & $23.7 \pm 6$ & $130.33 \pm 89.7$ \\
\hline
\end{tabular}

Values of the different clinical parameters did not differ between sildenafil and placebo arm

$B M I$ body mass index, HOMA $i$ Homeostasis model assessment index, $H b A l c$ Hemoglobin A1c, $H D L$ High-density lipoprotein, $L D L$ Lowdensity lipoprotein, $B P$ Blood pressure, $L V M i$ Left ventricular mass index, $E D V i$ End-diastolic volume index, $B N P$ brain natriuretic peptide, $N T$ proBNP N-terminal pro b-type natriuretic peptide

statins, etc.) were not changed between the months prior to the study and 1 month after it has finished. All blood samples were collected from peripheral vein and serum was obtained by centrifugation $(3000 \mathrm{rpm}$ for $10 \mathrm{~min}$ at $4{ }^{\circ} \mathrm{C}$ ); aliquots were stored at $-80{ }^{\circ} \mathrm{C}$ until analyzed.

One additional group of subjects, matched for sex and age, were analyzed for comparisons: 15 subjects without any pathology (healthy subjects). Written informed consent was collected for all subjects.

\section{Cell cultures}

Human fetal aortic endothelial cells (Hfaec) were obtained from aortic ascendant tracts collected after voluntary abortion (10-12 weeks of gestation) characterized and maintained as described elsewhere [14]. Legal abortions were performed in authorized hospitals; certificates of consent were obtained. The use of human fetal tissue for research purposes conforms with the principles outlined in the Declaration of Helsinki and was approved by the committee for investigation in humans of the Azienda Ospedaliero-Universitaria Careggi, Florence, Italy (protocol no. 6783-04).
Peripheral blood mononuclear cells (PBMCs) were isolated from buffy coats obtained from healthy adult anonymous donors in accordance with local ethical committee; approval by Azienda Policlinico Umberto I Rome Italy, accordance with the principles outlines in the Declaration of Helsinki; written consents were obtained. Heparinized blood, collected from peripheral vein, was centrifuged on Ficoll-Hystopaque gradient following manufacture's protocol. PBMCs were cultured in RPMI supplemented with $10 \%$ FBS, 2 mmol/l L-glutamine and antibiotics.

\section{IL-8 secretion assays}

\section{Serum determination}

Human serum levels of IL-8 were measured using a magnetic bead-based multiplex assay (Bio-Plex Pro ${ }^{\mathrm{TM}}$ Human Cytokine, Chemokine and Growth factor assay, Bio-Rad laboratories, Inc.) according to the manufacturer's protocol. A broad sensitivity range of standards (between 1.95 and $95.000 \mathrm{pg} / \mathrm{ml}$; Bio-Rad Laboratories, Inc.) was used to enable the quantification of a dynamic wide range of cytokine concentrations and provide the greatest sensitivity. Data acquisition was performed by Bio-Plex 200 System $^{\mathrm{TM}}$ (Bio-Rad Laboratories, Inc.) which uses Luminex fluorescent-bead-based technology (Luminex) with a flow-based dual laser detector with real-time digital signal processing to facilitate the analysis of up to 100 different families of color-coded polystyrene beads and allow multiple measurements of the sample ensuing in the effective quantification of cytokines. Data analysis was performed by Bio-Plex Manager ${ }^{\mathrm{TM}} 6.0$ software (Bio-Rad Laboratories, Inc.). Serum samples were run in triplicate at least twice. Data were expressed as serum IL- 8 concentration divided in "healthy" (subjects with no pathology), "baseline" (subjects with DCM before any therapy) and "+ sildenafil" and "+ placebo" (subjects with DCM and with sildenafil or placebo therapy after 3 months).

\section{Cell supernatant determination}

Hfaec (4000 cells/well) were seeded in 96-well flat bottom plates, maintained in phenol red- and serum-free medium overnight and incubated in serum-free medium containing $0.1 \%$ BSA with sildenafil $(1 \mu \mathrm{M})$ for $24-48 \mathrm{~h}$; cells in serumfree medium containing $0.1 \%$ BSA and vehicle were used as control.

PBMC (150,000 cells/well) were seeded in 96-well round bottom plates in their growth medium and stimulated with PHA $(2 \%)$ with or without sildenafil $(1 \mu \mathrm{M})$ for $24 \mathrm{~h}$ and $48 \mathrm{~h}$. Cells in growth medium with vehicle and PHA were used as controls. Sildenafil was added each day in each cell type. 
IL-8 levels were measured in cell cultures supernatants using commercially ELISA (enzyme-linked immunosorbent assay) available kits, according to the manufacturer's recommendations (R\&D Systems-Minneapolis). The sensitivity ranged was from 1.5 to $7.5 \mathrm{pg} / \mathrm{ml}$ for IL-8. The intra- and inter-assay coefficients of variation were 4.6 and 8.1\%. Quality control pools of low, normal, and high concentrations for all parameters were included in each assay. Samples were assayed in triplicate or quadruplicate. Protein measurement to normalize the concentration of secreted cytokines was performed as reported elsewhere [15]. Experiments were performed four times with different cell preparations. Data were expressed as percent of inhibition, calculated on IFN $\gamma+\mathrm{TNF} \alpha-$ and/or PHA release, taken as $100 \%$.

\section{RNA extraction, reverse transcription and real-time quantitative PCR}

35,000 Hfaec were seeded in 35-mm culture dishes and maintained for $24 \mathrm{~h}$ in their growth medium; after $12 \mathrm{~h}$ starvation (medium without serum and without phenol red), cells were stimulated for $24 \mathrm{~h}$ with a combination of IFN $\gamma$ $(1000 \mathrm{U} / \mathrm{ml})+\mathrm{TNF} \alpha(10 \mathrm{ng} / \mathrm{ml})$ with or without sildenafil $(1 \mu \mathrm{M})$, in serum-free medium with $0.1 \%$ BSA, cells in serum-free medium containing $0.1 \% \mathrm{BSA}$ and vehicle were used as control; 200,000 PBMC were seeded onto 96-well round bottom plates in their growth medium and stimulated for $48 \mathrm{~h}$ with $2 \%$ PHA with or without sildenafil $(1 \mu \mathrm{M})$, cells in growth medium and vehicle were used as control. Total RNA was extracted from cultured cells using TRIzol ${ }^{\circledR}$ RNA Isolation Reagents (Ambion ${ }^{\mathrm{TM}}$ ) according to the manufacturer's instructions and described also elsewhere [16]. Single-stranded cDNA was obtained by reverse transcription of $1 \mu \mathrm{g}$ of total RNA. RT-qPCRs were performed using 7500 Real Time System (Applied Biosystems ${ }^{\circledR}$ ) with SYBRgreen fluorophore; $40 \mathrm{ng}$ of cDNA were used as template and cycling parameters were $95{ }^{\circ} \mathrm{C}$ for $10 \mathrm{~min}$, followed by 40 cycles of $15 \mathrm{~s}$ at $95^{\circ} \mathrm{C}, 1 \mathrm{~min}$ at $60^{\circ} \mathrm{C}, 30 \mathrm{~s}$ at $95^{\circ} \mathrm{C}$, $15 \mathrm{~s}$ at $60^{\circ} \mathrm{C}$. Fluorescence intensities were analyzed using the manufacturer's software (7500 Software v2.05) and relative amounts were obtained using the $2-\Delta \Delta \mathrm{Ct}$ method and normalized for the $\beta$-actin. Data are expressed as percent of inhibition of IFN $\gamma+\mathrm{TNF} \alpha$ - or PHA-induced IL- 8 gene expression, taken as $100 \%$. Primers for IL- 8 were: forward (TCCTGATTTCTGCAGCTCTGTG) and reverse (GTC CAGCAGAGCTCTCTTCCAT); for $\beta$-actin, forward (CTG AACCCCAAGGCCAAC) and reverse (AGCCTGGATAGC AACGTACA).

\section{Cell proliferation}

For cell proliferation assay, Hfaec (4000 cells/well) and PBMC (150,000 cells/well) were seeded in 96-well flat and round bottom plates, respectively, as reported in cell supernatant determination subparagraph.

In each cell type, sildenafil was added each day. Cell number counting was assayed by hemocytometer as previously reported [17].

\section{Western blot analysis}

Hfaec and PBMC were seeded and maintained for western blot analysis, until they reach sufficient number to lyse in RIPA Buffer. Protein concentration measurement was performed with Bradford Reagent. Protein aliquots $(20 \mu \mathrm{g})$ were processed, loaded in $10 \%$ SDS-PAGE gel, transferred on nitrocellulose membranes, and incubated with primary Abs appropriately diluted in Tween Tris-buffered saline (TTBS; for anti-PDE5 1:500), followed by peroxidase-conjugated secondary $\operatorname{IgG}(1: 10,000)$. Proteins were revealed by the enhanced chemiluminescence system (ECL plus; Millipore). Image acquisition was performed with Image Quant Las 4000 software (GE Healthcare). Western blot analysis was performed for three experiments with different cell preparations.

\section{cGMP quantification}

cGMP determination has been performed onto $10^{6}$ cells after overnight starvation and 30 min incubation with or without sildenafil, using a commercially available kit (cGMP ELISA Kit from Enzo Life Sciences; Vinci, Fi, Italy) with 3-isobutyl-1-methylxanthine (IBMX) as internal positive assay control.

\section{Statistical analysis}

Our research was conceived as a "proof of concept" study. The statistical analysis was performed using 12.0 SPSS (SPSS Inc, Chicago, IL, USA). The Kolmogorov-Smirnov test was used to test for normal distribution of the data. Continuous data were compared using unpaired Student's $t$ test or Mann-Whitney test when request. Receiver operating characteristic (ROC) curve was constructed to assess the capacity of discriminating the response in terms of sildenafil-induced IL-8 decrease. Briefly, ROC curve gives a graphic representation of the relationship between truepositive fraction (sensitivity) and false-positive fraction (1-specificity). ROC curve can be assessed by plotting the values of 1-Sp against Se in a squared box, where the ROC's area under the curve (AUC) is used to measure the performance of a diagnostic test. The AUC range is in the interval $0.5-1.0$, so that the greater the area, the better the performance of the variable being examined. Sigmoid curves were performed using GraphPad Prism 5 software (GraphPad Software, Inc., La Jolla, CA, USA) and SPSS 12.0 software 
package. A $P$ value less than 0.05 was considered significant and corrected for comparison using the Dunnett's or Bonferroni's post hoc test, where appropriate. Data were expressed as mean $\pm \mathrm{SE}$.

\section{Results}

\section{IL-8 levels in healthy subjects and DCM patients before and after sildenafil or placebo intake}

To verify whether PDE5i could affect serum IL-8, we measured the chemokine blood level in DCM subjects before (baseline) and after sildenafil or placebo intake vs. healthy subjects.

In DCM patients, baseline IL-8 levels were about tenfold higher vs. healthy subjects $(149.14 \pm 46.89 \mathrm{pg} / \mathrm{ml}$ vs. $16.17 \pm 5.38 \mathrm{pg} / \mathrm{ml}, p<0.01$ ) (Fig. 1). Sildenafil after 3 months decreased IL- 8 close to similar values as found in healthy subjects $(23.7 \pm 6 \mathrm{pg} / \mathrm{ml}, p<0.05$ vs. baseline $)$, whereas placebo left essentially unvaried baseline IL- 8 in blood $(130.33 \pm 89.74 \mathrm{pg} / \mathrm{ml})$ of DCM patients.

\section{Assessment of IL-8 serum response to sildenafil in DCM patients}

To further estimate the effect of sildenafil in DCM patients, we analyzed IL- 8 serum level constructing ROC curve based on the response to sildenafil. Responders $(r)$ and non-responders $(n r)$ to sildenafil were defined as those

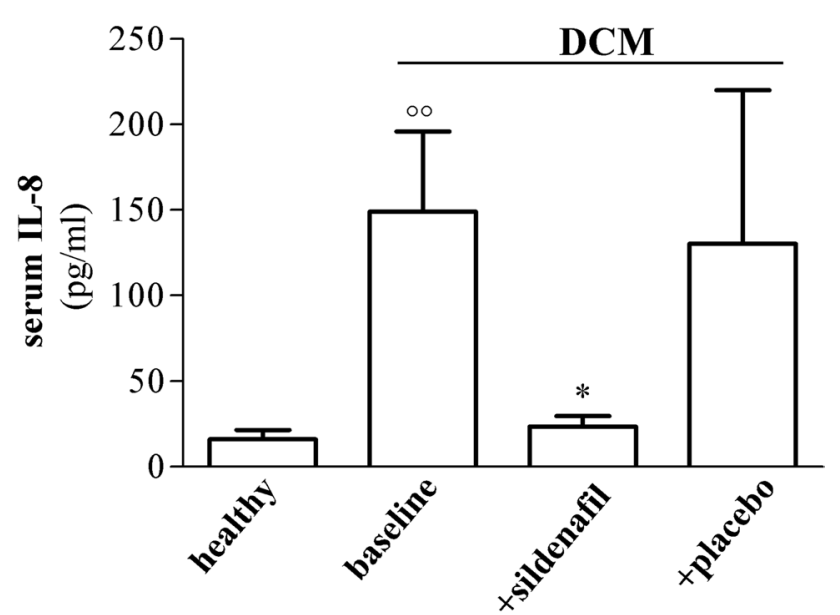

Fig. 1 Serum IL-8 levels in DCM patients before (baseline) and after 3 months sildenafil or placebo, vs. healthy subjects. DCM patients showed higher baseline levels of IL-8 vs. healthy subjects $(149.14 \pm 46.89 \mathrm{pg} / \mathrm{ml}$ vs. $16.17 \pm 5.38 \mathrm{pg} / \mathrm{ml}) ; \mathrm{IL}-8$ was significantly reduced $(23.7 \pm 6 \mathrm{pg} / \mathrm{ml})$ close to healthy levels in DCM patients after sildenafil. Conversely, serum IL-8 remained high after placebo $(130.33 \pm 89.74 \mathrm{pg} / \mathrm{ml}) .{ }^{*} p<0.05$ vs. baseline; ${ }^{\circ 0} p<0.01$ vs. healthy. Results (mean $\pm \mathrm{SE}$ ) are expressed as serum IL-8 (pg/ml) patients who had positive or null/negative response to the drug, respectively. $R$ and $\mathrm{nr}$ had IL-8 baseline value of $197.55 \pm 101.8 \mathrm{pg} / \mathrm{ml}$ and $-16.05 \pm 6.97 \mathrm{pg} / \mathrm{ml}$, respectively (Fig. 2a). Out of all clinical parameters analyzed, B-type natriuretic peptide (BNP), used as clinical biomarker for congestive heart failure diagnosis, was significantly higher in $\mathrm{r}$ vs. $\mathrm{nr}(p<0.05$, inset of Fig. 2a), albeit within normal range.
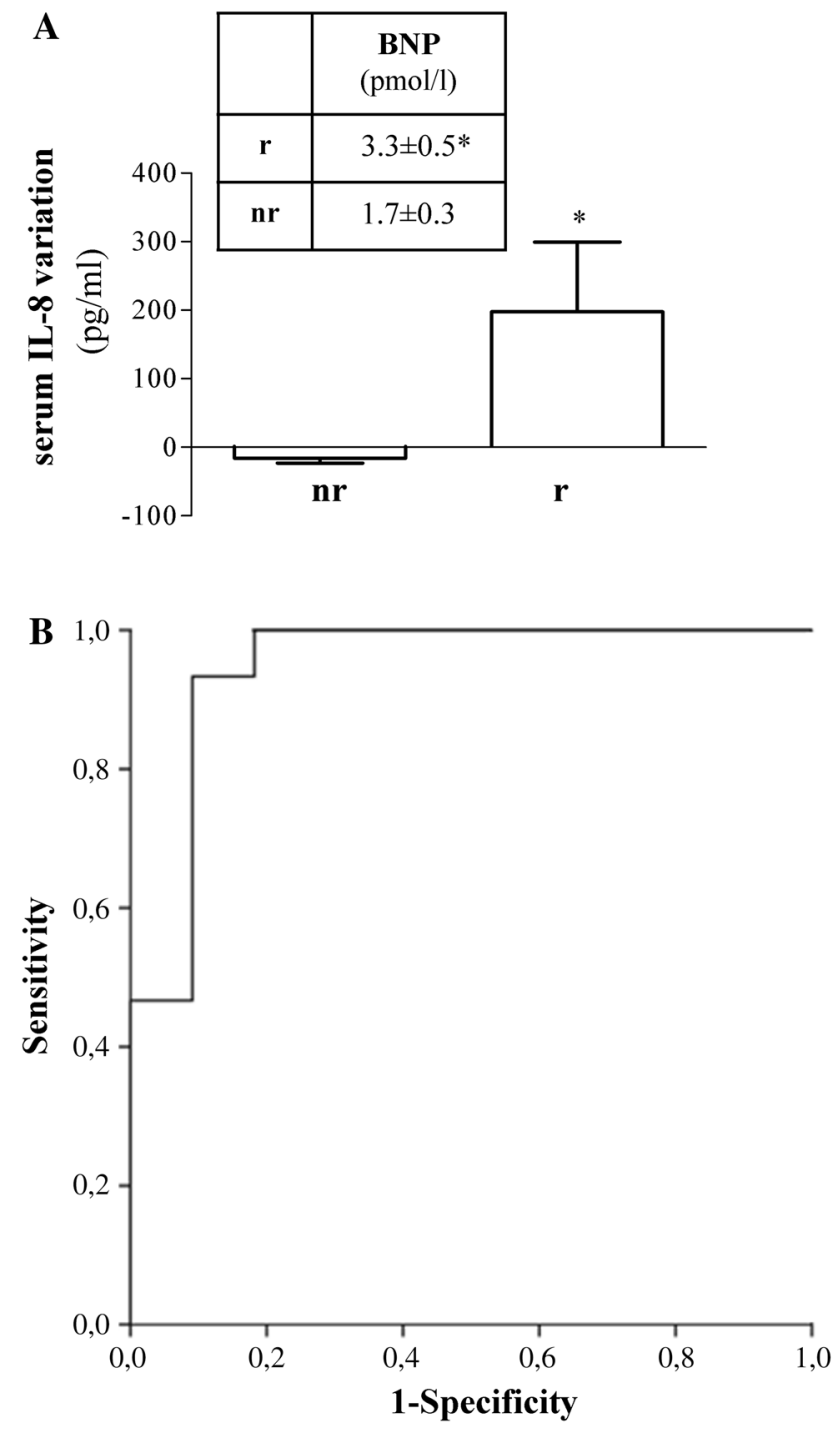

Fig. 2 Effect of sildenafil on circulating IL-8 in subjects with DCM. a IL-8 serum level categorized DCM patients as responders $(r)$ and non-responders $(n r)$ to sildenafil; positive $197.55 \pm 101.8 \mathrm{pg} / \mathrm{ml}$ ) or null/negative $(-16.05 \pm 6.97 \mathrm{pg} / \mathrm{ml})$ variation was observed after sildenafil intake; ${ }^{*} p<0.05 \quad r v s$. $n r$. Inset: Baseline BNP was significantly higher in $r$ vs. $n r, * p<0.05$. Data of IL-8 (mean $\pm \mathrm{SE})$ are expressed as serum variation vs. baseline level (pg/ml); BNP $($ mean $\pm \mathrm{SE}$ ) was expressed as pmol/l. b. Receiver operating characteristic (ROC) curve. The area under the ROC curve is 0.945 (95\% confidence interval of 0.772 to $1.0, p<0.01$ ), with a sensitivity of 0.93 and a specificity of 0.90 
Receiver operating characteristic (ROC) curve for IL-8 was 0.945 (95\% confidence interval of 0.772 to 1.0 , $p<0.01$ ), showing good capacity of discriminating the response in terms of drug-induced IL-8 decrease (sensitivity of 0.93 , specificity of 0.90 ) (Fig. $2 b$ ). ROC analysis identified a low IL-8 cut-off value $(12.25 \mathrm{pg} / \mathrm{ml})$.

\section{Effect of sildenafil onto IL-8 protein secretion and gene expression in Hfaec and PBMC}

To verify whether PDE5 inhibition might affect Th1-driven IL-8 at cellular level, we investigated the effect of sildenafil $(1 \mu \mathrm{M})$ onto chemokine protein secretion and gene expression in Hfaec and in PBMC after maximal inflammatory challenge (with IFN $\gamma+$ TNF $\alpha$ or PHA, respectively) (Fig. 3). Drug concentration was chosen based on the near therapy dose, according to pharmacokinetics (Cmax and area under the time-concentration curve).

Sildenafil significantly inhibited IL-8 protein release by over 50\% in Hfaec and 30\% in PBMC $(p<0.01$ and $p<0.001$ vs. inflammatory stimuli-induced secretion, taken as $100 \%$ ). IL-8 mRNA expression was also significantly reduced by sildenafil in PBMC ( $p<0.01$ vs. PHA-induced IL- 8 gene expression, taken as 1 ), whereas it was unaffected in Hfaec (inset of Fig. 3).

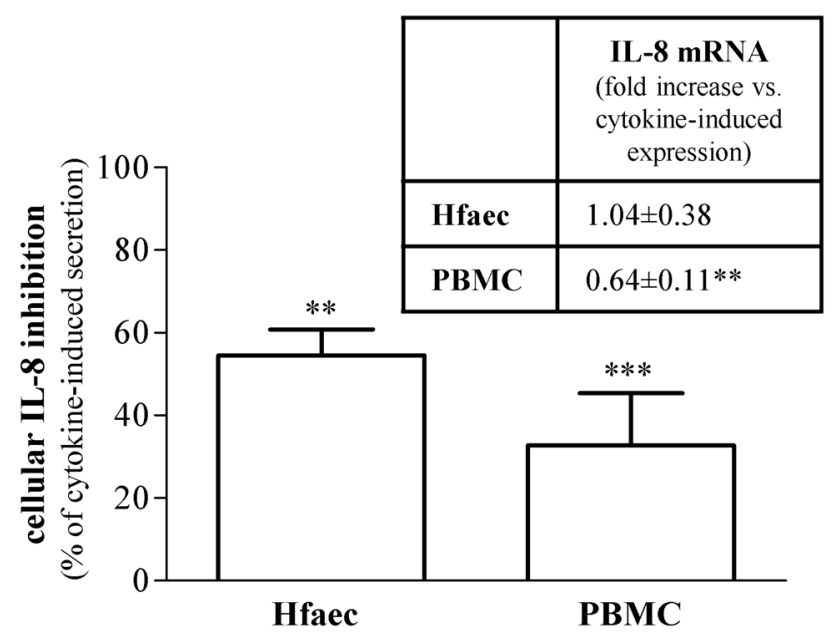

Fig. 3 Effect of sildenafil on IL-8 release induced by inflammatory stimuli in Hfaec and PBMC. IL-8 protein release was significantly counteracted by sildenafil in Hfaec and PBMC (percent of inhibition $54.54 \% \pm 1.09$ and $32.80 \% \pm 0.55)$; results (mean $\pm \mathrm{SE}$ ) are expressed as percent of inhibition, calculated on IFN $\gamma+\mathrm{TNF} \alpha-$ or PHA-induced IL-8 maximal secretion, taken as $100 \%$; *** $p<0.001$, $* * p<0.01$. Inset: IL-8 mRNA expression was reduced only in PBMC treated with sildenafil. mRNA levels-relative to $\beta$-actin mRNA, used as endogenous control-are expressed as (mean \pm SE) percent of inflammatory stimuli-induced IL-8 mRNA expression, taken as 1; $* * p<0.01$. Data are obtained from three to seven experiments in triplicate, using different cell preparations

\section{cGMP measurement and PDE5 expression before and after sildenafil in Hfaec and PBMC}

Since sildenafil is a selective cGMP-dependent inhibitor of PDE5 activity, we measured cGMP amount and PDE5 expression in human endothelial and immune cells before and after sildenafil (Fig. 4).

Sildenafil $(1 \mu \mathrm{M})$ significantly increased cGMP level after $30 \mathrm{~min}$ in Hfaec ( $p<0.05$ vs. control; Fig. 4a); cGMP in PBMC showed the same trend to rise after sildenafil, although not reaching statistical significance, like due to the high number variability linked to data deriving from isolated PBMC (Fig. 4b). PDE5 protein expression neither changed in Hfaec (inset of Fig. 4a) nor in PBMC (inset of Fig. 4b) after exposure to sildenafil $(1 \mu \mathrm{M})$ for $24 \mathrm{~h}$.

\section{Effect of sildenafil on Hfaec and PBMC cell number}

To exclude that sildenafil could affect human endothelial or immune cell number, we performed proliferation tests and found no significant effect in Hfaec and PBMC after 24-48 h exposure to sildenafil $(1 \mu \mathrm{M})$ as compared with control cells (Fig. 5a, b).

\section{Discussion}

The main finding of the study is that sildenafil, not placebo, significantly reduced the higher IL-8 serum concentration associated with DCM to similar levels as in healthy subjects. ROC curve for IL-8 showed good capacity to discriminate the response in terms of sildenafil-induced serum IL- 8 decrease. Furthermore, sildenafil inhibited IL-8 protein release by inflammation-activated human immune and endothelial cells, likely with transcriptional and posttranscriptional regulation.

The research onto inflammatory diseases has rapidly progressed in the last 50 years leading researchers and physicians to redefine many diseases as "inflammatory" disorders, including metabolic and heart diseases $[18,19]$. The concept of metaflammation as the first trigger common to several pathologies has come from growing evidence on the association between chronic inflammatory diseases and elevated blood levels of inflammatory markers [20, 21]. Th1 type chemokines regulate several inflammatory mechanisms considered the signature of metaflammation, essentially orchestrating immune cell recruitment and complex inter- and intracellular signaling. Among those biomediators, IL-8 or CXCL8, a prototypical chemoattractant component of ELR $+\mathrm{C}-\mathrm{X}-\mathrm{C}$ chemokine subfamily, derives from a variety of tissue and blood cells, and it is responsible for and involved in a wide range of inflammatory processes determining vascular bed homeostasis unbalance, with 



Fig. 4 Effect of sildenafil on cGMP stabilization and PDE5 expression. a cGMP concentration was significantly higher in Hfaec treated with sildenafil $(1 \mu \mathrm{M}, 30 \mathrm{~min}) ;{ }^{*} p<0.05$ vs. control cells. Inset Western blot analysis showed no changes of PDE5 protein expression in Hfaec before and after sildenafil; $\beta$-actin was used as loading control. b cGMP amount in PBMC after 30 min of sildenafil $(1 \mu \mathrm{M})$ showed a trend to increase though not statistically different vs. control. Inset

consequence on endothelial mediator release and vascular tone [22]. Remarkably, each cellular component in the vascular wall has been identified as a potential source of IL-8 significantly contributing to the inflammatory micro-environment maintenance of the injured vascular bed [3]. Differently from many other proinflammatory molecules, typically made and cleared in vivo within hours, IL-8 is present early and remains active for a prolonged time [3] during inflammatory response. IL-8 retains distinct target specificity for neutrophils which, once recruited, release granule enzymes degrading connective tissue constituents and determining intra- and extracellular injurious re-arrangements [23]. Transendothelial cell migration in chronic setting induced by IL-8 underlies endothelial dysfunction, as reported in several
Western blot analysis showed no changes in PDE5 protein expression before and after sildenafil; $\beta$-actin was is the loading control. Results in panel A (mean \pm SE) are expressed as cGMP concentration (pmol/106 cells) and derived from two different preparations for each cell type; the blots in panel $\mathbf{a}$ and $\mathbf{b}$ are representative of data deriving from two/three different preparations of both cell types

vascular diseases, from atherosclerosis, to aortic aneurysm formation and hypertension [24].

Thus far, since endothelial instability underlies cardiac disease in the presence or absence of comorbidity [25, 26], the ability of sildenafil to counteract vascular inflammation by targeting IL- 8 could potentially be of clinical interest. Previous data showed that daily administration of sildenafil reduced vascular inflammation and improved endothelial function in T2D patients [27]. Clinical evidence sustains a strong association between PDE5i use and reduced mortality rate and hospitalization in a cohort of T2D patients with attendant high cardiovascular risk [28]. PDE5 inhibition seems also to exert favorable effects by enhancing enzymatic antioxidant system capacity [29]. Of note, those 


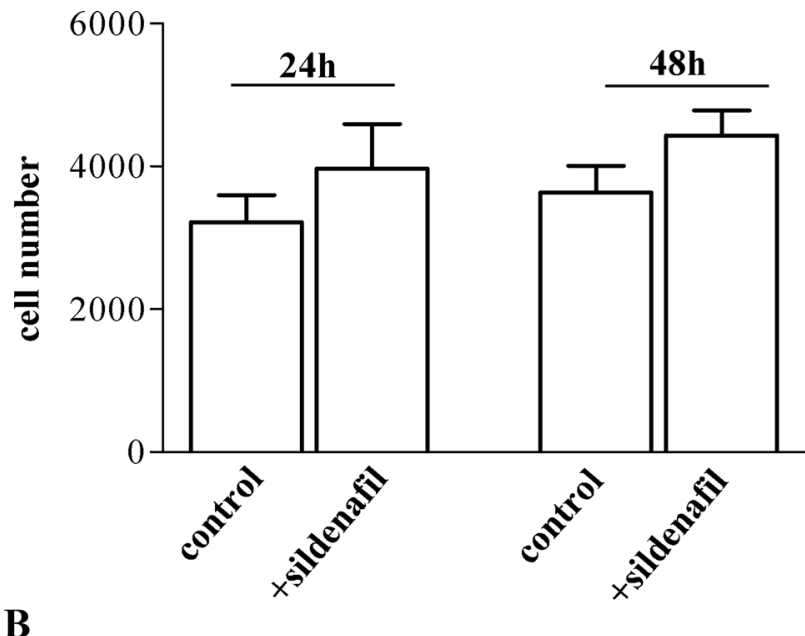

B

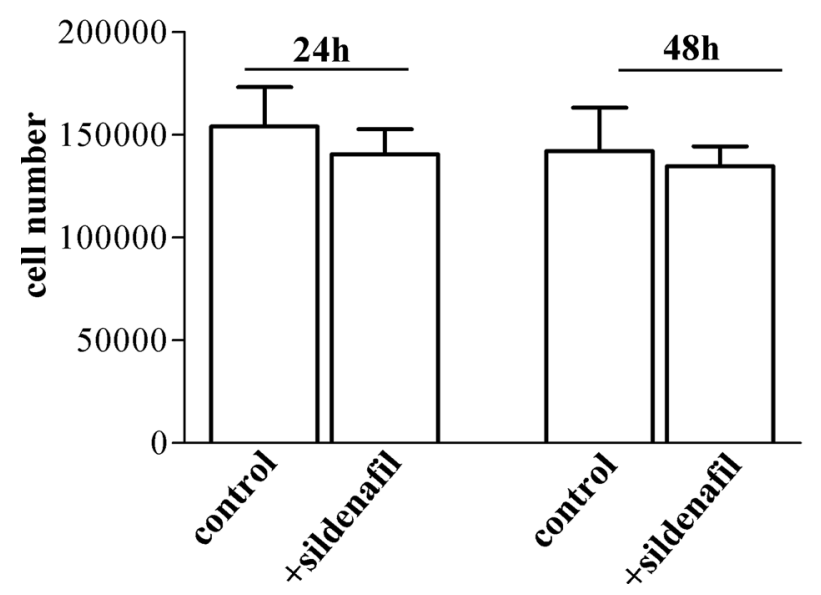

Fig. 5 Effect of sildenafil on human cardiac, endothelial and immune cell viability. a Hfaec cell number did not change after sildenafil $(1 \mu \mathrm{M})$ for $24 \mathrm{~h}$ or $48 \mathrm{~h}$ vs. control (without drug). b PBMC cell number was not modified by sildenafil $(1 \mu \mathrm{M})$ after $24 \mathrm{~h}$ and $48 \mathrm{~h}$ vs. control cells. Results derived from at least four different cell preparations for each cell type and are expressed as $($ mean $\pm \mathrm{SE})$

effects were not achieved with other class of vasoactive drugs as prostaglandins.

Concerning IL-8 cut-off low level $(12.25 \mathrm{pg} / \mathrm{ml})$, we observed that it was below the mean IL-8 concentration found in healthy subjects. Thus, we only can speculate that DCM patients would get benefit from sildenafil in terms of chemokine decrease when their baseline IL- 8 value is much higher than that cut-off level.

Of note, the majority of DCM subjects classified as $r$ to sildenafil concerning serum IL-8 level was previously grouped as $r$ to the drug in terms of serum CXCL10, a Th1 type ERL chemokine [9], and also retained higher baseline $\mathrm{BNP}$, although still within normal reference range.

We speculate that DCM subjects showing from the beginning higher Th1-type inflammatory chemokines might be perhaps more prone to progress in cardiomyopathy.
Moreover, sildenafil significantly counteracted IL-8 protein release from endothelial and immune cells-both known sources of the chemokine contributing to amplify inflammation-likely through post-transcriptional mechanism(s) in Hfaec, and transcriptional regulation in PBMC.

While in Hfaec sildenafil effect is undeniably mediated by cGMP stabilization as reflected by the significant increase, cGMP rise in sildenafil-treated PBMC, albeit showing a trend to increase, did not reach statistical significance, likely due to high number variability. PDE5 protein expression was not modified by sildenafil in either cell type in line with the previous literature [30]. However, detectable increase in PDE5 protein expression is reported after longer times (up to 7-days incubation) and higher dosage $(25 \mu \mathrm{M})[31,32]$.

In conclusion, from the present and previous data, sildenafil is able to target high level of ERL +/ERL-C-XC chemokines, as IL-8 and CXCL10, both known to play pivotal roles in initiation and progression of micro-environmental immune/inflammatory processes leading to self-detrimental perpetuating loops established between local and systemic areas [33-35].

We would like to point out the potential clinical impact of C-X-C chemokine targeting, since those biomolecules act as immune/inflammatory triggers starting from an early temporal frame, likely preceding clinical cardiac sign manifestation. Indeed, while sildenafil modified metabolic parameters such as Hemoglobin A1c, post-prandial glycemia and lipidemic profile [36], it failed to modify standard markers of chronic cardiac decompensation, such as ejection fraction, mass and volume index or blood pressure. We speculate on this (lacking) effect considering that all DCM patients enrolled were at the initial stage of cardiac disease, with no clinical signs of ischemia and left ventricular (LV) function well preserved.

Accordingly, it has been shown that T2D man with ED still asymptomatic for cardiovascular disease showed higher monocyte oxidative activity and endothelial dysfunction [37], both additionally reduced with sildenafil given in combination with L-carnitine [38].

Likely, medium/long term follow-up would reveal whether sildenafil-induced IL-8 inhibition in blood could possibly relate with variation of some clinical parameters associated with patient status.

In addition, further medium/long-term investigations likely will elucidate whether the lack of any modification of circulating IL- 8 after 4 weeks of sildenafil in T2D patients, as previously reported [39] could be possibly explained with differences in treatment, including timeframe and protocols.

So far, our results support the hypothesis that sildenafil could be a good candidate as a therapeutic option (may be as sparing-agent?) in patients with metabolic disorders, including comorbid conditions, at increased risk of cardiovascular 
abnormalities, often ameliorated by testosterone replacement $[40,41]$. Furthermore, sildenafil retains a better cardiovascular profile vs. other PDE5i, as demonstrated by well-established overall safety after its use, with the limitation to avoid co-administration with long- and short-acting nitrate preparations [42]. More recently, it has been reported in animals that PDE5 inhibition by sildenafil, not tadalafil, decreased edema in lung ischemia-reperfusion injury during cardiopulmonary blocks [43].

Our investigation has several limits besides the small sample size analyzed, first the lack of subjects affected by T2D or cardiomyopathy alone with and without sildenafil treatment. Moreover, considering the high number of biomediators engaged in metaflammation during comorbid conditions, it is mandatory to analyze a combination/ratio of biomediators. As an example, when evaluating vascular homeostasis and inflammation in diabetes, it is mandatory to consider molecules such as angiopoietins, critically involved in those processes [44]. Indeed, integrated analysis including an amplified number of noninvasive biomarkers aimed to obtain implemented algorithms has been recognized since a while to retain better predictive values, useful for validated decision models in several diseases $[45,46]$. Due to their positive impact on both patients health care and efficient use of resources, standard risk algorithms incorporating different type of biomarkers, i.e., including sex/gender-related variables, are nowadays strongly encouraged also in T2D and its complications [47-49]. In this direction, we are planning our future investigations. Finally, the observed cut-off value of IL-8 resulted very low and below the mean IL- 8 concentration found in healthy subjects. Hence, we believe that our findings are to be mitigated and taken cautiously, as they need to be confirmed in larger sample size studies.

Nevertheless, previous and present data suggest that sildenafil could be recommended with the novel indication to control metabolic status and early stage inflammatory processes underlying DCM and warrant further in vivo and in vitro studies on PDE5i-promoted cardioprotection to assess the related fine-tuned biomolecular mechanisms.

Acknowledgements Clinical Trial Registration-URL: http://www.clini caltrials.gov. Unique identifier: NCT00692237.

Funding This work was partially supported by the Scientific Independence of young Researchers (SIR) under Grant no. RBSI14D5NX.

\section{Compliance with ethical standards}

Conflict of interest The authors declare that they have no conflict of interest.

Ethical approval All procedures performed in studies involving human participants were in accordance with the ethical standards of the institutional and/or national research committee and with the 1964 Helsinki Declaration and its later amendments or comparable ethical standards.
Informed consent Informed consent was obtained from all individual participants involved in the study.

Open Access This article is distributed under the terms of the Creative Commons Attribution 4.0 International License (http://creativeco mmons.org/licenses/by/4.0/), which permits unrestricted use, distribution, and reproduction in any medium, provided you give appropriate credit to the original author(s) and the source, provide a link to the Creative Commons license, and indicate if changes were made.

\section{References}

1. Prattichizzo F, De Nigris V, Spiga R et al (2018) Inflammageing and metaflammation: the yin and yang of type 2 diabetes. Ageing Res Rev 41:1-17. https://doi.org/10.1016/j.arr.2017.10.003

2. Hotamisligil GS (2017) Inflammation, metaflammation and immunometabolic disorders. Nature 542(7640):177-185. https://doi. org/10.1038/nature21363

3. Apostolakis S, Vogiatzi K, Amanatidou V et al (2009) Interleukin 8 and cardiovascular disease. Cardiovasc Res 84(3):353-360. https://doi.org/10.1093/cvr/cvp241

4. Bruun JM, Lihn AS, Madan AK et al (2004) Higher production of IL-8 in visceral vs. subcutaneous adipose tissue. Implication of nonadipose cells in adipose tissue. Am J Physiol Endocrinol Metab 286(1):8-13. https://doi.org/10.1152/ajpendo.00269.2003

5. Velásquez IM, Frumento P, Johansson K et al (2014) Association of interleukin 8 with myocardial infarction: results from the Stockholm Heart Epidemiology Program. Int J Cardiol 172(1):173-178. https://doi.org/10.1016/j.ijcard.2013.12.170

6. Cimini FA, Barchetta I, Porzia A et al (2017) Circulating IL-8 levels are increased in patients with type 2 diabetes and associated with worse inflammatory and cardiometabolic profile. Acta Diabetol 54(10):961-967. https://doi.org/10.1007/s00592-017-1039-1

7. Varma A, Shah KB, Hess ML (2012) Phosphodiesterase inhibitors, congestive heart failure, and sudden death: time for re-evaluation. Congest Heart Fail 18(4):229-233. https://doi.org/10.111 1/j.1751-7133.2012.00293.x

8. Moore AR, Willoughby DA (1995) The role of cAMP regulation in controlling inflammation. Clin Exp Immunol 101(3):387-389

9. Di Luigi L, Corinaldesi C, Colletti M et al (2016) Phosphodiesterase Type 5 inhibitor sildenafil decreases the proinflammatory chemokine CXCL10 in human cardiomyocytes and in subjects with diabetic cardiomyopathy. Inflammation 39(3):1238-1252. https://doi.org/10.1007/s10753-016-0359-6

10. Corinaldesi C, Di Luigi L, Lenzi A et al (2016) Phosphodiesterase type 5 inhibitors: back and forward from cardiac indications. J Endocrinol Invest 39(2):143-151. https://doi.org/10.1007/s4061 8-015-0340-5

11. Das A, Durrant D, Salloum FN et al (2015) PDE5 inhibitors as therapeutics for heart disease, diabetes and cancer. Pharmacol Ther 147:12-21. https://doi.org/10.1016/j.pharmthera .2014 .10 .003

12. Rao YJ, Xi L (2009) Pivotal effects of phosphodiesterase inhibitors on myocyte contractility and viability in normal and ischemic hearts. Acta Pharmacol Sin 30(1):1-24. https://doi.org/10.1038/ aps.2008.1

13. Giannetta E, Isidori AM, Galea N et al (2012) Chronic Inhibition of cGMP phosphodiesterase 5A improves diabetic cardiomyopathy: a randomized, controlled clinical trial using magnetic resonance imaging with myocardial tagging. Circulation 125(19):2323-2333. https://doi.org/10.1161/CIRCULATIO NAHA.111.063412 
14. Scolletta S, Buonamano M, Sottili M et al (2012) CXCL10 release in cardiopulmonary bypass: an in vivo and in vitro study. Biomed Aging Pathol 2(187-94):7. https://doi.org/10.1016/j.bioma g.2011.07.001

15. Crescioli C, Cosmi L, Borgogni E et al (2007) Methimazole inhibits CXC chemokine ligand 10 secretion in human thyrocytes. J Endocrinol 195(1):145-155. https://doi.org/10.1677/JOE-07-0240

16. Mannelli M, Ferruzzi P, Luciani P et al (2003) Cushing's syndrome in a patient with bilateral macronodular adrenal hyperplasia responding to cisapride: an in vivo and in vitro study. J Clin Endocrinol Metab 88(10):4616-4622. https://doi.org/10.1210/ jc.2002-021949

17. Marchiani S, Bonaccorsi L, Ferruzzi P et al (2006) The vitamin D analogue BXL-628 inhibits growth factor-stimulated proliferation and invasion of DU145 prostate cancer cells. J Cancer Res Clin Oncol 132(6):408-416. https://doi.org/10.1007/s0043 2-006-0086-8

18. Ueland T, Gullestad L, Nymo SH et al (2015) Inflammatory cytokines as biomarkers in heart failure. Clin Chim Acta 30(443):71-77. https://doi.org/10.1016/j.cca.2014.09.001

19. Caroselli C, De Rosa R, Tanzi P et al (2016) Endothelial immunomediated reactivity in acute cardiac ischaemia: role of endothelin 1 , interleukin 8 and NT-proBNP in patients affected by unstable angina pectoris. Int J Immunopathol Pharmacol 29(3):516-522. https://doi.org/10.1177/0394632015608247

20. Ansar W, Ghosh S (2013) C-reactive protein and the biology of disease. Immunol Res 56(1):131-142. https://doi.org/10.1007/ s12026-013-8384-0

21. Laveti D, Kumar M, Hemalatha R et al (2013) Anti-inflammatory treatments for chronic diseases: a review. Inflamm Allergy Drug Targets 12(5):349-361

22. Signorelli SS, Fiore V, Malaponte G (2014) Inflammation and peripheral arterial disease: the value of circulating biomarkers (review). Int J Mol Med 33(4):777-783. https://doi.org/10.3892/ ijmm.2014.1657

23. Tecchio C, Cassatella MA (2014) Neutrophil-derived cytokines involved in physiological and pathological angiogenesis. Chem Immunol Allergy 99:123-137. https://doi.org/10.1159/000353358

24. Sprague AH, Khalil RA (2009) Inflammatory cytokines in vascular dysfunction and vascular disease. Biochem Pharmacol 78:539-552. https://doi.org/10.1016/j.bcp.2009.04.029

25. Ganz P, Hsue PY (2013) Endothelial dysfunction in coronary heart disease is more than a systemic process. Eur Heart $\mathrm{J}$ 34:2025-2027. https://doi.org/10.1093/eurheartj/eht199

26. Hadi HA, Carr CS, Al SJ (2005) Endothelial dysfunction: cardiovascular risk factors, therapy, and outcome. Vasc Health Risk Manag 1(3): 183-198

27. Santi D, Giannetta E, Isidori AM et al (2015) Therapy of endocrine disease. Effects of chronic use of phosphodiesterase inhibitors on endothelial markers in type 2 diabetes mellitus: a meta-analysis. Eur J Endocrinol 172(3):103-114. https://doi. org/10.1530/eje-14-0700

28. Anderson SG, Hutchings DC, Woodward M et al (2016) Phosphodiesterase type- 5 inhibitor use in type 2 diabetes is associated with a reduction in all-cause mortality. Heart 102(21):1750-1756. https://doi.org/10.1136/heartjnl-2015-309223

29. Duranti G, Ceci R, Sgrò $P$ et al (2017) Influence of the PDE5 inhibitor tadalafil on redox status and antioxidant defense system in C2C12 skeletal muscle cells. Cell Stress Chaperones 22(3):389-396. https://doi.org/10.1007/s12192-017-0778-9

30. Luong C, Rey-Perra J, Vadivel A et al (2011) Antenatal sildenafil treatment attenuates pulmonary hypertension in experimental congenital diaphragmatic hernia. Circulation 123(19):2120-2131. https://doi.org/10.1161/CIRCULATIONAHA.108.845909
31. Lin CS (2004) Tissue expression, distribution, and regulation of PDE5. Int J Impot Res 16(Suppl 1):S8-S10. https://doi. org/10.1038/sj.ijir.3901207

32. Lin G, Xin ZC, Lue TF, Lin CS (2003) Up and down-regulation of phosphodiesterase- 5 as related to tachyphylaxis and priapism. J Urol. 170(2 Pt 2):S15-S18. https://doi.org/10.1097/01.ju.00000 75500.11519.e8 (discussion S19)

33. Frangogiannis NG, Entman ML (2005) Chemokines in myocardial ischemia. Trends Cardiovasc Med 15(5):163-169. https://doi. org/10.1016/j.tcm.2005.06.005

34. Crescioli C, Buonamano A, Scolletta S et al (2009) Predictive role of pretransplant serum CXCL10 for cardiac acute rejection. Transplantation 87(2):249-255. https://doi.org/10.1097/TP.0b013 e3181919f5d

35. Scolletta S, Colletti M, Di Luigi L et al (2013) Vitamin D receptor agonists target CXCL10: new therapeutic tools for resolution of inflammation. Mediators Inflamm 876319:1-11. https://doi. org/10.1155/2013/876319

36. Mandosi E, Giannetta E, Filardi T et al (2015) Endothelial dysfunction markers as a therapeutic target for Sildenafil treatment and effects on metabolic control in type 2 diabetes. Expert Opin Ther Targets 19(12):1617-1622. https://doi.org/10.1517/14728 222.2015.1066337

37. Morano S, Gatti A, Mandosi E et al (2007) Circulating monocyte oxidative activity is increased in patients with type 2 diabetes and erectile dysfunction. J Urol 177(2):655-659. https://doi. org/10.1016/j.juro.2006.09.046

38. Morano S, Mandosi E, Fallarino M et al (2007) Antioxidant treatment associated with sildenafil reduces monocyte activation and markers of endothelial damage in patients with diabetic erectile dysfunction: a double-blind, placebo-controlled study. Eur Urol 52(6):1768-1774. https://doi.org/10.1016/j.eururo.2007.04.042

39. Burnett AL, Strong TD, Trock BJ et al (2009) Serum biomarker measurements of endothelial function and oxidative stress after daily dosing of sildenafil in type 2 diabetic men with erectile dysfunction. J Urol 181(1):245-251. https://doi.org/10.1016/j. juro.2008.09.005

40. Rossoni G, Manfredi B, De Gennaro CV et al (2007) Sildenafil reduces L-NAME-induced severe hypertension and worsening of myocardial ischaemia-reperfusion damage in the rat. Br J Pharmacol 150(5):567-576. https://doi.org/10.1038/sj.bjp.0707131

41. Calogero AE, Giagulli VA, Mongioì LM et al (2017) Klinefelter syndrome: cardiovascular abnormalities and metabolic disorders. J Endocrinol Invest 40(7):705-712. https://doi.org/10.1007/s4061 8-017-0619-9

42. Kukreja RC, Ockaili R, Salloum F et al (2004) Cardioprotection with phosphodiesterase-5 inhibition-a novel preconditioning strategy. J Mol Cell Cardiol 36(2):165-173. https://doi.org/10.1016/j. yjmcc.2003.11.001

43. Guerra-Mora JR, Perales-Caldera E, Aguilar-León D (2017) Effects of sildenafil and tadalafil on edema and reactive oxygen species production in an experimental model of lung ischemiareperfusion injury. Transpl Proc 49(6):1461-1466. https://doi. org/10.1016/j.transproceed.2017.03.089

44. Isidori AM, Venneri MA, Fiore D (2016) Angiopoietin-1 and Angiopoietin-2 in metabolic disorders: therapeutic strategies to restore the highs and lows of angiogenesis in diabetes. J Endocrinol Invest 39(11):1235-1246. https://doi.org/10.1007/s4061 8-016-0502-0

45. Han JH, Nachamkin I, Coffin SE et al (2015) Use of a combination biomarker algorithm to identify medical intensive care unit patients with suspected sepsis at very low likelihood of bacterial infection. Antimicrob Agents Chemother 59(10):6494-6500. https ://doi.org/10.1128/AAC.00958-15 
46. Cohen Freue GV, Meredith A, Smith D et al (2013) Computational biomarker pipeline from discovery to clinical implementation: plasma proteomic biomarkers for cardiac transplantation. PLoS Comput Biol 9(4):e1002963. https://doi.org/10.1371/journ al.pcbi.1002963

47. Osahon IS (2017) Review: biomarkers and role in the prediction and detection of type 2 diabetes and its complications. Biomark $\mathbf{J}$ 3(2):11. https://doi.org/10.21767/2472-1646.100033

48. Peddinti G, Cobb J, Yengo L et al (2017) Early metabolic markers identify potential targets for the prevention of type 2 diabetes.
Diabetologia 60(9):1740-1750. https://doi.org/10.1007/s0012 5-017-4325-0

49. Scirica BM, Bhatt DL, Braunwald E et al (2016) Prognostic implications of biomarker assessments in patients with type 2 diabetes at high cardiovascular risk: a secondary analysis of a randomized clinical trial. JAMA Cardiol 1(9):989-998. https:// doi.org/10.1001/jamacardio.2016.3030 